\title{
Exploration of the Transition Temperatures and Crystal Structure of Highly Crystalline Poly(1,3-cyclohexadiene): An Experimental and Computational Investigation
}

\author{
Bohdan Schatschneider, ${ }^{\mathrm{a} \dagger}$ Robert T. Mathers, ${ }^{\mathrm{b}}$ Richard H. Gee ${ }^{\mathrm{c}}$, and Nichole M. Wonderling ${ }^{\mathrm{d}}$ \\ ${ }^{a}$ Department of Chemistry, The Pennsylvania State University, The Eberly Campus, Lemont Furnace, PA \\ 15401 . \\ ${ }^{b}$ Department of Chemistry, The Pennsylvania State University, New Kensington, PA 15068. \\ ${ }^{c}$ Lawrence Livermore National Laboratory, Livermore, CA 94551. \\ ${ }^{d}$ Materials Research Institute, The Pennsylvania State University, University Park, PA 16802
}

\begin{abstract}
:
Experimental determination of transition temperatures for highly crystalline polymers such as poly-1,3-cyclohexadiene (PCHD) can be difficult due to reduced solubility and thermalization processes which occur during data acquisition. In order to facilitate further understanding of these processes for PCHD, density functional theory (DFT) and molecular dynamics (MD) were used in conjunction with differential scanning calorimetry (DSC) and powder X-ray diffraction (XRD) to explore the oligomer microstructures, the crystal structure, and the temperature dependence of the specific volume $(1 / \rho)$. DFT geometry minimizations on isolated oligomers were used to identify the lowest energy confirmer; revealing that alternating R,R and S,S chiral bonds between monomer units afford the lowest energy structure. MD simulations of crystalline PCHD were constructed so as to replicate the experimental XRD pattern of crystalline PCHD, with the best fit producing a monoclinic crystal structure. The temperature dependence of the specific volume derived from MD simulations provided insight into the glass/vitrification $\left(\mathrm{T}_{\mathrm{g}}\right)$ and melting $\left(\mathrm{T}_{\mathrm{m}}\right)$ transition temperatures. Comparison of the simulation transition temperatures with differential scanning calorimetry data of PCHD polymerized with $\mathrm{Ni}$ (acac) 2 /MAO shows good agreement and solidifies the fidelity of the newly defined PCHD crystalline structure.
\end{abstract}

TITLE RUNNING HEAD: Highly Crystalline Poly(1,3-cyclohexadiene).

†Corresponding Author: bxs54@psu.edu. 


\section{Introduction}

Crystallinity in polymeric systems has enormous significance in chemistry, biology, and materials science. ${ }^{1-3}$ It profoundly affects the physical properties and thermal stabilities ${ }^{4-6}$ of polymeric materials, and is influenced by factors such as stereoregularity, ${ }^{7}$ pi-pi stacking, ${ }^{8}$ mainchain rigidity, ${ }^{9}$ end-group dependence, ${ }^{10}$ and hydrogen bonding. ${ }^{11}$ An illustrative example of crystallinity's influence on polymer properties resides in stereoregular polyolefins; where high crystallinity improves solvent resistance, high-temperature performance, and degradation time. ${ }^{12}$ Conversely, crystallinity reduces solubility and makes characterization more challenging. This is exemplified in the need for elevated temperatures in measuring NMR spectra or obtaining molecular weight data via gel permeation chromatography (GPC) of stereoregular polyolefins. The high crystallinity observed in these materials also makes identification of the glass/vitrification $\left(\mathrm{T}_{\mathrm{g}}\right)$, crossover/melt-to-crystal $\left(\mathrm{T}_{\mathrm{c}}\right)$ and melting $\left(\mathrm{T}_{\mathrm{m}}\right)$ transition temperatures challenging via DSC as decomposition processes can occur before the transitions are witnessed.

Highly crystalline polyolefins containing cyclic monomer units [e.g. cyclopentene, ${ }^{13}$ norbornene, ${ }^{14}$ and 1,3-cyclohexadiene $\left.(1,3-\mathrm{CHD})^{15}\right]$ possess tunable physical properties and improved optical transparency. Of particular interest is poly-1,3-CHD (PCHD), which can contain varying amounts of 1,2- and 1,4-cyclohexene units depending on the polymerization method. The alkenes in these 1,2- and 1,4-cyclohexene units allow for modification of the physical properties through a multitude of post-polymerization chemical reactions. ${ }^{16-20}$ The resulting polymers have shown physical properties suitable for use in optoelectronic applications as well as proton exchange membranes for fuel cells. ${ }^{21-23}$

As shown in Scheme 1, several methods to synthesize diene monomers such as 1,3-CHD from plant oils were recently reported. ${ }^{24-27}$ These catalytic procedures avoid stoichiometric reagents, organic solvents, and halogenated waste to provide higher atom economy than elimination reactions (i.e. dehydrohalogenation) or the Birch reduction of benzene. ${ }^{27,28}$

The degree of regio- and stereoregularity in polyolefins strongly influences polymer solubility in organic solvents as well as $\mathrm{T}_{\mathrm{m}}$ and $\mathrm{T}_{\mathrm{g}}{ }^{29}{ }^{29}$ Typically, polymerization of 1,3-CHD with $\mathrm{Ni}(\mathrm{acac})_{2} / \mathrm{MAO}$ catalysts provides crystalline PCHD with a high degree of regio- and stereoregularity, as evidenced by the large $\mathrm{T}_{\mathrm{m}}$ values..$^{15,30-32}$ Elucidation of the microstructure by NMR and molecular modeling confirmed that the $\mathrm{Ni}(\mathrm{acac})_{2} / \mathrm{MAO}$ catalyst system resulted in PCHD with high cis-1,4-addition. ${ }^{32-34}$ As a consequence, the high degree of stereo- and 
regioselectivity can make many solution-based characterization methods inoperable or require elevated temperatures in chlorinated solvents.

\section{Polyunsaturated plant oils}
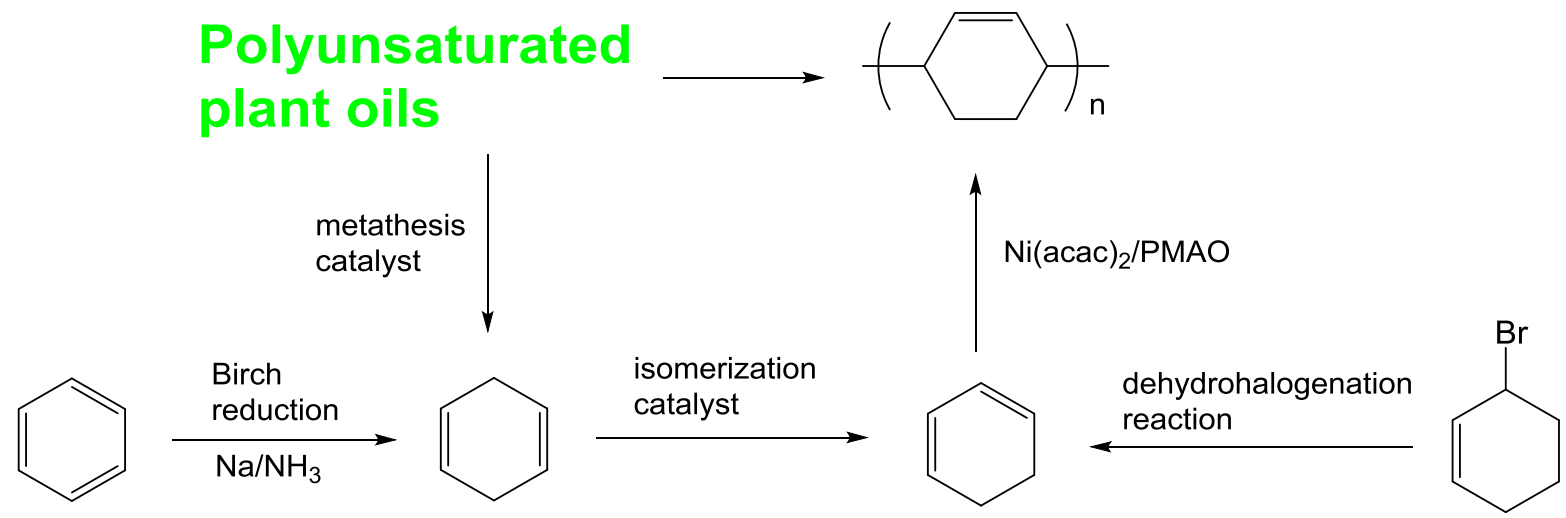

Scheme 1. Plant oil-based strategy for renewable 1,3-cyclohexadiene avoids Birch reduction and dehydrohalogenation.

Previously, characterization of PCHD made from plant oil employed FTIR-ATR and DSC (Figure S1) due to the difficulty associated with solution-based methods. ${ }^{24,35}$ Informative as these methods are, several unanswered questions remained regarding the polymer microstructure, molecular weight, and thermal transitions (since erasing the thermal history on the first DSC heating cycle approaches the decomposition temperature). As a result, we have utilized density functional theory (DFT) and molecular dynamics (MD) simulations on isolated oligomers and bulk PCHD crystals and entangled melts for comparison with differential scanning calorimetry (DSC) and powder X-ray diffraction (XRD) in order to gain insight into the most stable oligomer microstructure, crystal structure, and thermal transitions of highly crystalline PCHD.

\section{Methodology}

2.1. Homopolymer Energy Calculations. In an attempt to evaluate the relative stabilities of different PCHD oligomer conformational states, we used DFT calculations to examine a variety of PCHD oligomer structures in terms of their geometry optimized structures and relative energies. All DFT calculations were performed using $\mathrm{DMol}^{3}$ within the Materials Studio suite V6.0.0 produced by Accelrys Inc. Various sized CHD oligomers, as described in Scheme 2 of Ref. 30, were geometry optimized and vibrational analysis of homopolymers was conducted within the 
$\mathrm{DMol}^{3}$ module. The structures were optimized in three steps using a GGA-PBE functional with an octupole multipolar expansion. The density mixing charge was 0.2 , with a spin of 0.5 , and a DIIS size of 6. The SCF tolerances, basis set, and global orbital cutoffs were progressively changed to ensure the structure was in a local minimum. SCF tolerances were therefore decreased from $1.0 \times 10^{-4}$, to $1.0 \times 10^{-5}$, ending at $1.0 \times 10^{-6}$ (at which point a local minimum was met as confirmed via vibrational analysis). An all electron treatment was used, starting with a DN basis set, followed by a DND basis set, ending with a DNP basis set. The global orbital cutoffs progressed from $3.0 \AA$, to $3.3 \AA$, to $3.7 \AA$. Frequency calculations were performed by diagonalizing the mass-weighted second-derivative matrix, ${ }^{36}$ confirming that the structures were in a local minimum.

2.2. Polymer Simulations. With the goal of obtaining quantitative agreement between the temperature dependence of the specific volume derived from MD simulations and differential scanning calorimetry data, various different PCHD simulation ensembles were investigated.

The Materials Studio suite V6.0.0 (Accelrys, Inc., San Diego, CA) was used to prepare the simulation ensembles, where all MD simulations were carried out using the LAMMPS (Largescale Atomic/Molecular Massively Parallel Simulator) software package. ${ }^{37,38}$ All MD simulations employed the PCFF force field ${ }^{39}$ for all atom-atom interactions.

The MD simulations of PCHD were carried out on both crystalline and bulk amorphous ensembles, where all atoms in the ensembles were treated explicitly. The bulk amorphous simulations were performed on eight 160-mer CHD chains (molecular weight, MW=12,823 g/mol; 17,936 total number of atoms) using cubic periodic boundary conditions. Bulk structures used in the MD were as described in Section 3.2. Using this ensemble as the crystalline PCHD unit cell, a $4 \times 2 \times 1$ 'super-cell' was created so as to investigate the temperature dependence of crystalline PCHD. Specifically, thirty-two 4-mer PCHD chains (1,792 atoms) were place into a periodic simulation cell ( $a=39.6 \AA, b=36.0 \AA, c=15.9 \AA, \alpha=\gamma=90^{\circ}$, and $\left.\beta \approx 139^{\circ}\right)$, and simulated using constant particle number, pressure, and temperature $(N P T)^{40}$ dynamics at a pressure of $0 \mathrm{~Pa}$, where all six simulation cell dimensions $(x, y, z, x y, x z, y z)$ were allowed to adjust independently. A time step of $1.0 f s$ was used for all simulations. The nonbonded van der Waals interactions were treated by truncating atom pairs with an inter-atomic distance greater than $10 \AA$, coupled with a longrange tail correction. ${ }^{41}$ The particle-particle particle-mesh Ewald (PPPM) method $^{42}$ was used for the long-range treatment of electrostatic interactions with a k-space accuracy set at $10^{-5}$. 
Simulated X-ray diffraction patterns were acquired using the Powder Diffraction tools within Accelrys' Materials Studio Reflex Module.

2.3. DSC Method. DSC was performed on a TA instruments $\mathrm{Q} 20$ at heating rates of 0.5 $\mathrm{K} / \mathrm{min}$ - $10 \mathrm{~K} / \mathrm{min}$ under nitrogen flow $(30 \mathrm{~mL} / \mathrm{min})$. The polymer samples $(2-3 \mathrm{mg})$ were measured in TZero aluminum pans that were crimped under ambient conditions.

2.4. PCHD Synthetic Method. The polymerization was run for $30 \mathrm{~min}$ at $363 \mathrm{~K}$ with neat 1,3-cyclohexadiene made from soybean oil. As indicated in Ref. ${ }^{24}$, the polycyclohexadiene was made in neat cyclohexadiene with $\mathrm{Ni}(\mathrm{acac})_{2} / \mathrm{MAO}$ catalyst system $([\mathrm{Ni}]:[\mathrm{Al})=1: 100)$.

2.5. XRD Method. The specimen was prepared by light grinding in a mortar and pestle and then placed into the cavity of a silicon low background diffraction plate. X-ray diffraction patterns were collected on a PANalytical X'Pert Pro MPD theta-theta X-ray diffractometer equipped with a PIXcel line detector, fixed slits $\left(1 / 4^{\circ}\right.$ divergence, $1 / 2^{\circ}$ incident anti-scatter $)$ and Ni-filter, a $\mathrm{Cu}$ K- $\alpha$ source, and a curved graphite diffracted beam monochromator in reflection mode. Results and Discussion

\section{Results and Discussion}

3.1. PCHD Oligomer Optimizations. It has been suggested that four PCHD microstructures (Scheme 2 of Ref. 30) are possible. ${ }^{30}$ In order to evaluate the relative stabilities of each, we optimized PCHD oligomers and examined their relative energies and structures. Figure 1 demonstrates the tetramers of all maximum order microstructures. Calculations began with the dimer of each scheme and the convergence criteria was increased stepwise until vibrational analysis confirmed that the structures were in a local minimum. Monomer units were then sequentially added after each successful optimization to the minimized structure until reaching a hexamer of each array. Table 1 demonstrates the relative energies of the various constructs. It is interesting to note that dimers containing an $(S, S)$ linkage produce the lowest energy, followed by $(R, S)$ and finally $(R, R)$.

A relationship exists between the inter-monomer anti-hydrogen torsion angles and the relative energies of a given dimer. Table 1 shows that $(S, S)$ linkages produce the highest torsion angles between the 'anti' hydrogens of bound monomers, in turn producing the lowest relative energy dimers. $(R, S)$ linkages produce both the next largest torsion angle and lowest energy dimers, followed by $(R, R)$ linkages. It follows then, that Scheme 2c of Figure 1 would be highest 
in energy as all inter-monomer bonds are $(R, R)$ linkages. Schemes $2 \mathrm{a}$ and $2 \mathrm{~d}$ both depend exclusively on $(R, S)$ linkages, resulting in inter-monomer torsion angles and energies who's relative values interchange depending on the oligomer chain length. Finally, Scheme $2 b$ is dependent on $(R, R)$ and $(S, S)$ linkages, this results in a bimodal distribution of torsion angles within the structure; i.e., the $(S, S)$ linkages produce torsion angles of $\sim 172^{\circ}$ while the $(R, R)$ linkages produce angles of $\sim 164^{\circ}$. This varies from the other structures as they all produce unimodal distributions, where all torsion angles only vary $\pm 1.0^{\circ}$ from the average.

Despite the fact that stereoregularity during 1,3-CHD polymerizations has been suggested, ${ }^{30}$ the calculations show that non-regular cis-addition of monomer units can produce multiple microstructures that are energetically similar. Nonetheless, a clear structural energetic trend is observable; i.e., the $2 \mathrm{~b}$ structure is calculate to be the most stable, followed by $2 \mathrm{a}, 2 \mathrm{~d}$, and finally $2 \mathrm{c}$. This may result from the fact that the $2 \mathrm{~b}$ isomer has $(S, S)$ linkages while none of the other microstructures do. The observed trend correlates well with previous speculations that either $2 \mathrm{a}$ or $2 \mathrm{~b}$ are the most probable structures (assuming cis-addition). ${ }^{30}$

Table 1

\begin{tabular}{|c|c|}
\hline $\begin{array}{c}\text { Stereochemistry } \\
\text { (torsion angle) }\end{array}$ & PCHD oligomer structure \\
\hline $\begin{array}{c}\text { R,SR,SR,S (2a) } \\
\left(-166.704^{\circ},-165.143^{\circ},-166.220^{\circ}\right)\end{array}$ & \\
\hline $\begin{array}{c}\text { R,RS,SR,R (2b) } \\
\left(-165.319^{\circ},-171.773^{\circ},-162.306^{\circ}\right)\end{array}$ & \\
\hline $\begin{array}{c}\text { R,RR,RR,R (2c) } \\
\left(-165.371^{\circ},-164.727^{\circ},-166.065^{\circ}\right)\end{array}$ & \\
\hline
\end{tabular}




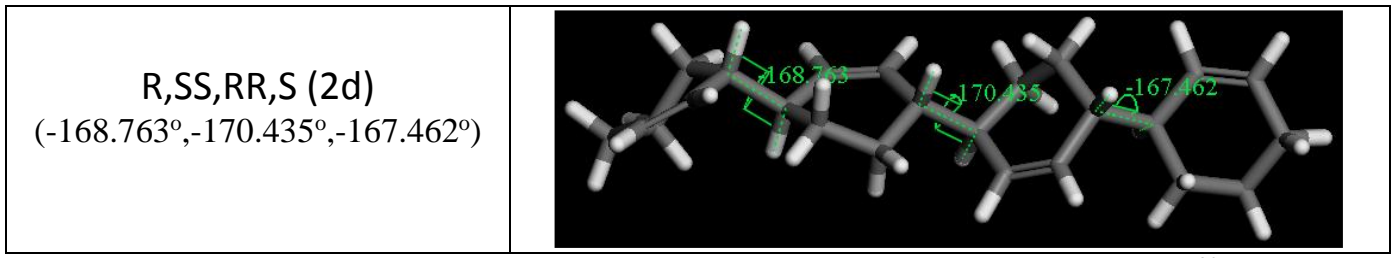

Figure 1. Possible stereochemistry for tetramers as described according to Scheme $2 .{ }^{30}$ Comma in stereochemistry column indicates new monomer unit. Torsion angles (blue) represent the antihydrogen structure between CHD rings.

Despite the fact that stereoregularity during 1,3-CHD polymerizations has been suggested ${ }^{30}$ the calculations show that non-regular cis-addition of monomer units can produce multiple microstructures that are energetically similar. Nonetheless, a clear structural energetic trend is observable; i.e., the $2 \mathrm{~b}$ structure is calculate to be the most stable, followed by $2 \mathrm{a}, 2 \mathrm{~d}$, and finally $2 \mathrm{c}$. This may result from the fact that the $2 \mathrm{~b}$ isomer has $(S, S)$ linkages while none of the other microstructures do. The observed trend correlates well with previous speculations that either $2 \mathrm{a}$ or $2 \mathrm{~b}$ are the most probable structures (assuming cis-addition). ${ }^{30}$

Table 1. Relative energies of PCHD oligomers. The parenthetical designation (2a-d) correlates to Scheme $2 .{ }^{30}$ Comma in stereo-structure indicates a link between monomeric units.

\begin{tabular}{|c|c|c|}
\hline Stereochemistry & $\begin{array}{l}\text { Relative Energy } \\
\text { (kcal/mol) }\end{array}$ & $\begin{array}{l}\text { Average Inter- } \\
\text { monomer Torsion } \\
\text { angle }\left({ }^{\circ}\right)\end{array}$ \\
\hline \multicolumn{3}{|l|}{ Dimer } \\
\hline$R, \overline{S(2 a, 2 d)}$ & 0.135 & 166.976 \\
\hline$R, R(2 b, 2 c)$ & 0.273 & 164.081 \\
\hline $\mathrm{S}, \mathrm{S}(2 \mathrm{~b})$ & 0 & 172.075 \\
\hline \multicolumn{3}{|l|}{ Trimer } \\
\hline R,SR,S (2a) & 0.121 & 167.478 \\
\hline$R, R S, S(2 b)$ & 0 & 166.913 \\
\hline R,RR,R (2c) & 0.546 & 163.874 \\
\hline$R, S S, R(2 d)$ & 0.016 & 167.861 \\
\hline \multicolumn{3}{|l|}{ Tetramer } \\
\hline$R, \overline{S R, S R, S(2 a)}$ & 0 & 166.022 \\
\hline R,RS,SR,R (2b) & 0.040 & 166.466 \\
\hline$R, R R, R R, R(2 c)$ & 0.646 & 165.368 \\
\hline$R, S S, R R, S(2 d)$ & 0.024 & 168.887 \\
\hline \multicolumn{3}{|l|}{ Pentamer } \\
\hline $\mathrm{R}, \mathrm{SR}, \overline{\mathrm{SR}, \mathrm{SR}, \mathrm{S}}(2 \mathrm{a})$ & 0.039 & 166.916 \\
\hline$R, R S, S R, R S, R(2 b)$ & 0 & 167.733 \\
\hline$R, R R, R R, R R, R(2 c)$ & 0.873 & 163.671 \\
\hline R,SS,RR,SS,R (2d) & 0.006 & 165.972 \\
\hline Hexamer & & \\
\hline
\end{tabular}




\begin{tabular}{|ccc|}
\hline R,SR,SR,SR,SR,S (2a) & 0.078 & 165.505 \\
\hline R,RS,SR,RS,SR,R (2b) & 0 & 167.289 \\
\hline R,RR,RR,RR,RR,R (2c) & 1.170 & 163.375 \\
\hline R,SS,RR,SS,RR,S (2d) & 0.210 & 166.110 \\
\hline
\end{tabular}

3.2. Bulk Structure Determination. No reference structure data for poly-cyclohexadiene exists; therefore XRD was performed in concert with MD simulations in an effort to elucidate the structure of the material. The percent crystallinity was estimated from the diffraction pattern in Figure 2 at $\sim 50 \%$ by profile fitting the region between 10 and $30^{\circ} 2-\theta$ with pseudo-voigt profiles, assuming an amorphous component with a FWHM of $7^{\circ}$ centered at $18.3^{\circ} 2-\theta$. This agrees well with previously reported crystallinity values of $\sim 60 \%{ }^{30}$ for PCHD made with $\mathrm{Ni}(\mathrm{acac})_{2} / \mathrm{MAO}$.

The diffraction pattern shown in Figure 2 consists of three broad peaks that alone cannot be used to confirm the structures within the crystalline domains of PCHD. In order to clearly identify the space group and unit cell dimensions of the crystal structure via XRD, an extensive study utilizing orientated samples as a function of temperature would be necessary: This is beyond the scope of this investigation. However, as shown below (and in other studies ${ }^{43,44}$ ), direct-space methods - MD simulations coupled with peak fitting procedures - can be used in concert with lower resolution XRD to accurately predict crystalline structure.

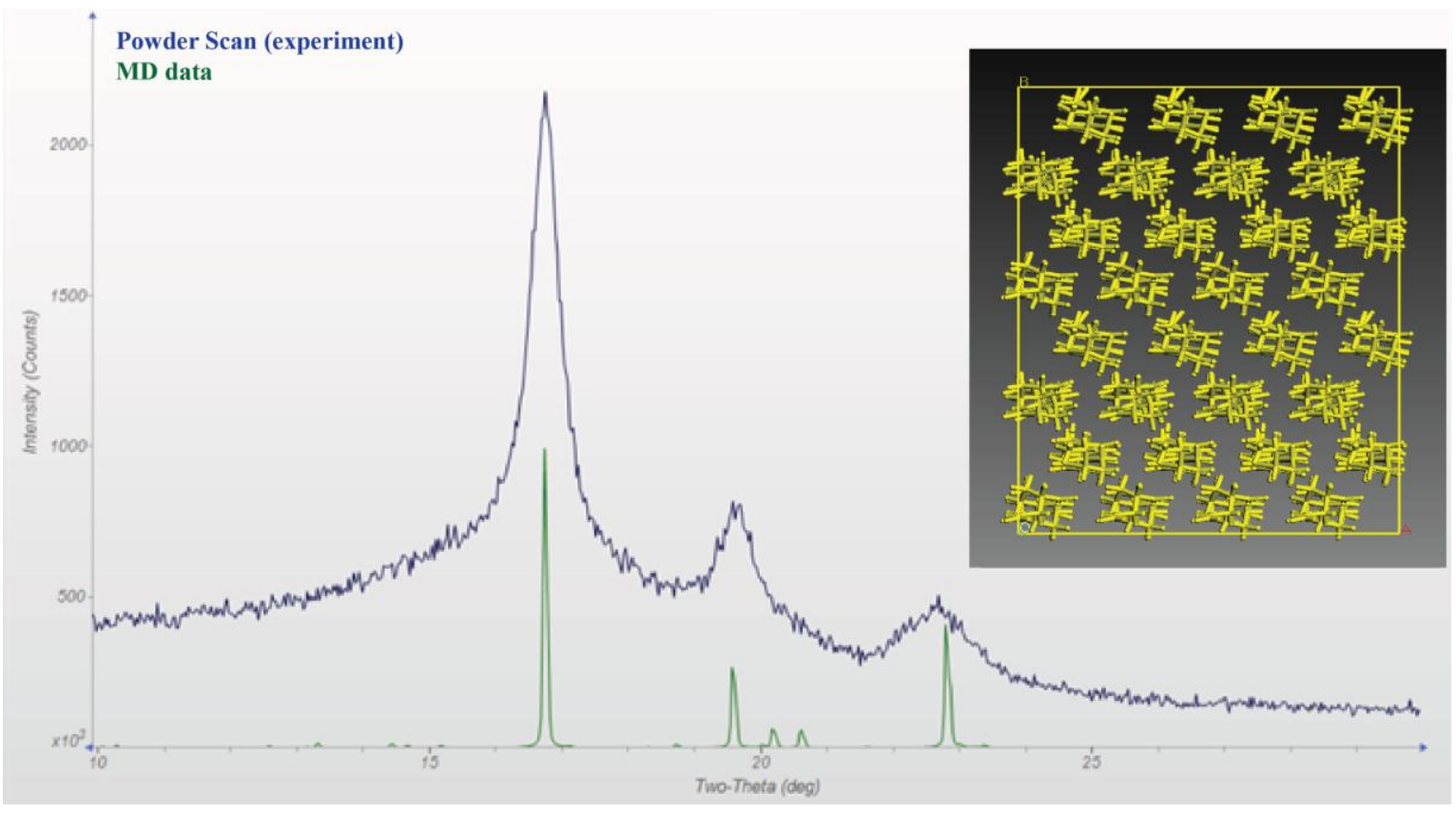


Figure 2. X-ray diffraction pattern of poly(1,3-cyclohexadiene) at $300 \mathrm{~K}$ as obtained from experiment (solid black line) and from simulation (solid green line) with copper $\mathrm{K}_{\alpha}$ radiation (wavelength $=1.5406$ $\AA$ ). The inset shows the resultant $4 \times 2 \times 1$ crystalline PCHD super-cell used in all crystalline simulations reported here.

In order to acquire a realistic bulk structure for further MD simulations, crystalline PCHD ensembles were constructed in silico so as to reproduce the experimental PCHD XRD pattern. To this end, annealing simulations were performed on ensembles composed of 4-mer CHD chains (structure $2 \mathrm{~b}$ in Table 1), where the chains were modeled as 'infinite' MW chains due to the bonding across the $c$-axis of the periodic unit cell. The results of these simulations produced a monoclinic unit cell containing four 4-mer PCHD chains with lattice parameters of $a=9.9 \AA$, $b=18.0 \AA, c=15.9 \AA$ and $\alpha=\gamma=90^{\circ}, \beta \approx 139^{\circ}$ as the best fit to the experimental XRD pattern (see Figure 2). Interestingly, the predicted monoclinic structure used in the proceeding simulations resembles the linearly packed structures existing within the lamalle folds of highly ordered poly(vinylidene fluoride) $)^{45,46}$ and polyethylene. ${ }^{46,47}$.

3.3. Thermal Transitions of PCHD. The glass transition temperatures of amorphous PCHD with $100 \%$ 1,4-microstructure $\left(\mathrm{T}_{\mathrm{g}}=369 \mathrm{~K}\right), 80 \%$ 1,4-microstructure $\left(\mathrm{T}_{\mathrm{g}}=403 \mathrm{~K}\right)$, and $49 \%$ 1,4-microstructure $\left(\mathrm{T}_{\mathrm{g}}=418 \mathrm{~K}\right)$, are readily obtainable via $\mathrm{DSC}^{29}$. However, experimentally establishing the transition temperatures of highly crystalline morphologies of 100\% 1,4 PCHD (as reported here) has been a challenge. One can see in Figure 3 that the typical baseline shift for a $\mathrm{T}_{\mathrm{g}}$ is not observed in the DSC of highly crystalline (100\%) 1,4 PCHD (even when the heating rate is slowed to $0.5 \mathrm{~K} / \mathrm{min}$ ).

In contrast to the difficulty involved with establishing $\mathrm{T}_{\mathrm{g}}$, Figure $\mathbf{3}$ clearly shows a crystallization exotherm $\left(\mathrm{T}_{\mathrm{c}}\right)$ and melting endotherm $\left(\mathrm{T}_{\mathrm{m}}\right)$ for highly crystalline PCHD. $\mathrm{T}_{\mathrm{c}}$ correlates well with previously reported values ${ }^{48}$ of $\sim 405 \mathrm{~K}$ for $95 / 5$ mixtures of $1,4 \mathrm{PCHD} / 1,2$ PCHD. To confirm $T_{c}$ and $T_{m}$ and gain clearer insight into $T_{g}$, a second thermal cycle was performed, as it is known that a second run can "fingerprint" the phase states. Unfortunately, upon heating PCHD above $\mathrm{T}_{\mathrm{m}}$ (erasing the thermal history), decomposition processes occur, resulting is a second run with no discernable features (similar to previous investigations ${ }^{48}$ ).

Due to the difficulty in fingerprinting the transition temperatures of highly crystalline PCHD with DSC, MD simulations were implemented to allow for systematic exploration of $\mathrm{T}_{\mathrm{g}}$ and $T_{m}$. Explicitly, the temperature dependence of the specific volume $(1 / \rho)$ of PCHD was 
investigated as breaks occurring in the temperature dependent slopes of this parameter are useful in identifying thermal transitions. ${ }^{45,49-56}$ Here, the highly ordered 'crystalline' PCHD structure discussed above (Section 3.2) was utilized as a starting structure.

The simulated crystal contained thirty-two 4-mer PCHD units, and was initially simulated at $300 \mathrm{~K}$ under $N P T$ conditions for a minimum of $\sim 30 \mathrm{~ns}$ at a pressure of $0 \mathrm{~Pa}$ until equilibrated (see Figure 2 inset). The specific volume of the system at $300 \mathrm{~K}$ was determined to be $0.873 \mathrm{~cm}^{3} / \mathrm{g}$, within 3-9\% of experiment $\left(0.898-0.955 \mathrm{~cm}^{3} / \mathrm{g}\right.$ (see Table Error! Reference source not found.)). This agreement is quite good given no attempts were made to calibrate the PCFF potential energy parameters. Following this step, the ensemble was heated in $N P T$ runs in increments of $50 \mathrm{~K}$ and equilibrated for a minimum of $\sim 30 n s$ each at the desired temperature $(350 \mathrm{~K}, 400 \mathrm{~K}, 450 \mathrm{~K}, 500$ $\mathrm{K}$, and $550 \mathrm{~K}$ ). Additional simulations were also performed at $575 \mathrm{~K}, 585 \mathrm{~K}$, and $590 \mathrm{~K}$. When heated to a temperature of $590 \mathrm{~K}$, the crystalline structure began to disorder and melt (see Figure 4 and Figure 5).

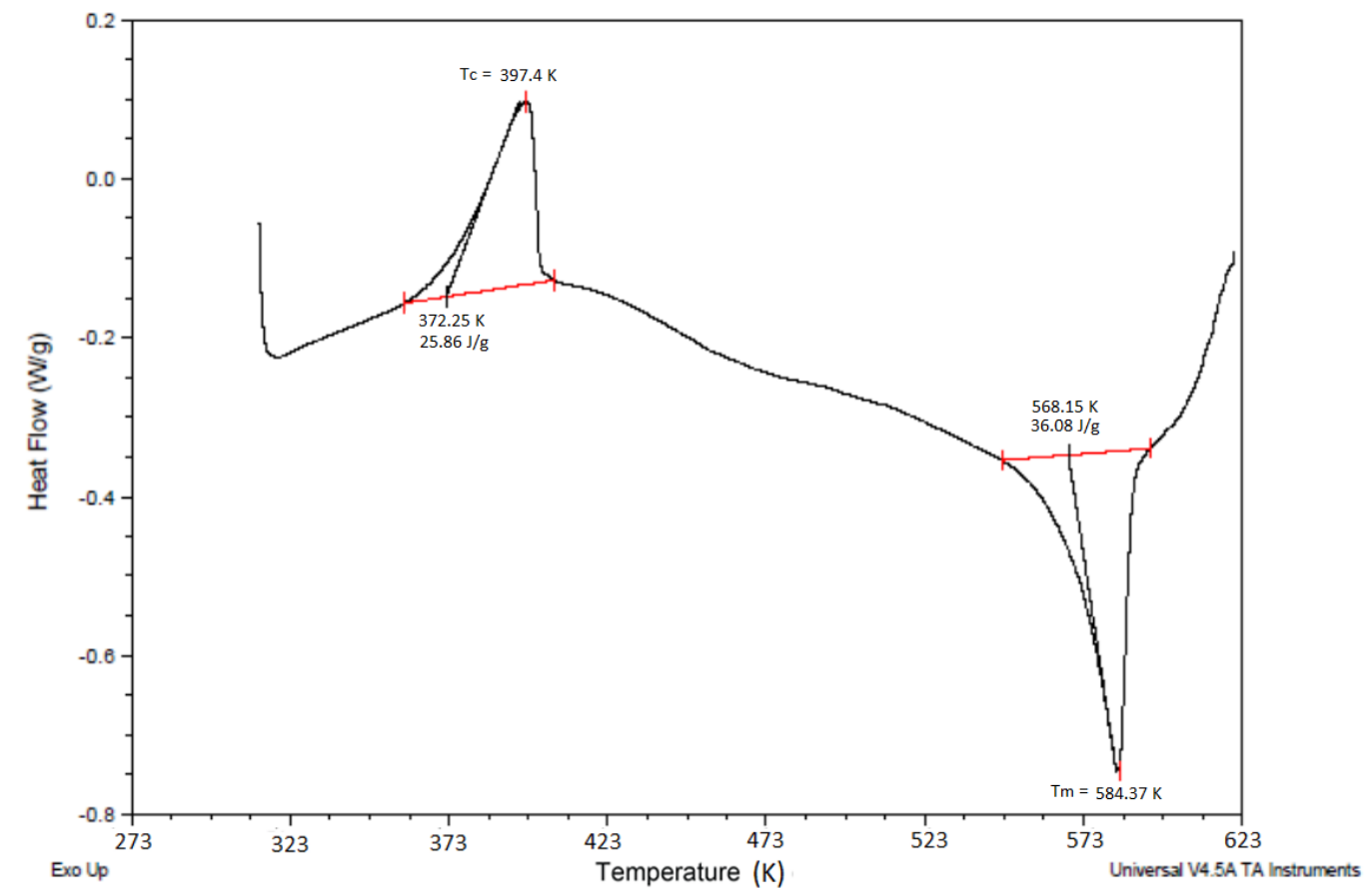

Figure 3. DSC analysis ( $10 \mathrm{~K} / \mathrm{min}$, exo up) for polycyclohexadiene made in neat cyclohexadiene. The polymerization (entry 4 in Table 1 of reference ${ }^{24}$ ) was conducted with $\mathrm{Ni}(\mathrm{acac})_{2} / \mathrm{MAO}$ catalyst system ([Ni]: $[\mathrm{Al})=1: 100)$ at $363 \mathrm{~K}$. The $\mathrm{T}_{\mathrm{c}}$ and $\mathrm{T}_{\mathrm{m}}$ values, $\sim 397.4 \mathrm{~K}$ and $584.4 \mathrm{~K}$, are labeled in the first DSC heating cycle; both $\mathrm{T}_{\mathrm{g}}$ and $\mathrm{T}_{\mathrm{m}}$ are absent from second heating cycles indicating that the crystalline regions were fully melted in the first heating cycle and did not undergo crystallization during the cooling or second heating cycle. For comparison, Figures S2, S3, and S4 show the DSC results for other polymerizations at $363 \mathrm{~K}, 323 \mathrm{~K}$, and $296 \mathrm{~K}$, respectively. 
To illustrate the melt onset of the crystalline PCHD simulation ensemble at $590 \mathrm{~K}$, the ensemble lattice dimensions (shown in Figure 4 as a function of time during the NPT MD simulations) undergo significant dimensional change after $\sim 10 \mathrm{~ns}$. Further, the calculated melt onset temperature at $\sim 590 \mathrm{~K}$ is consistent with the endotherm occurring at $584 \mathrm{~K}$ in the DSC of Error! Reference source not found.3 and the results of other $\mathrm{T}_{\mathrm{m}}$ measurements $\left(588 \mathrm{~K}^{30}\right)$ of highly crystalline/stereoregular PCHD.

To identify $\mathrm{T}_{\mathrm{g}}$, the amorphous 160-mer PCHD structures outlined in Section 2.2 were implemented. The initial polymer melt density was chosen to be less than expected for experimental melt densities at the corresponding temperature as a lower initial density state has been found to improve the convergence of equilibration procedures by avoiding initial high-energy configurations. ${ }^{45,46}$ The amorphous structure was initially simulated at $590 \mathrm{~K}$ and allowed to relax under NPT conditions for a minimum of $15 n s$ at a pressure of $0 \mathrm{GPa}$. Following this step, the melts were cooled in NPT runs in increments of $50 \mathrm{~K}$, to a temperature of $350 \mathrm{~K}$, and in increments of $25 \mathrm{~K}$ to a temperature of $275 \mathrm{~K}$ and equilibrated for a minimum of $15 \mathrm{~ns}$ each at the desired temperature $(550 \mathrm{~K}, 500 \mathrm{~K}, 450 \mathrm{~K}, 400 \mathrm{~K}, 350 \mathrm{~K}, 325 \mathrm{~K}, 300 \mathrm{~K}$, and $275 \mathrm{~K})$. The resultant calculated specific volumes $(1 / \rho)$ as a function of temperature are shown in Figure 5. The volume vs. temperature curve shows a distinct break, characteristic of vitrification - similar to those found in previous MD simulations of other polymeric systems ${ }^{45,51,53-56}$. The calculated $\mathrm{T}_{\mathrm{g}}$ of $\sim 360 \mathrm{~K}$ correlates well with previously reported $\mathrm{T}_{\mathrm{g}}$ values ${ }^{48}$ of $344-390 \mathrm{~K}$ for $95 / 5$ mixtures of 1 ,4PCHD/1,2-PCHD. 


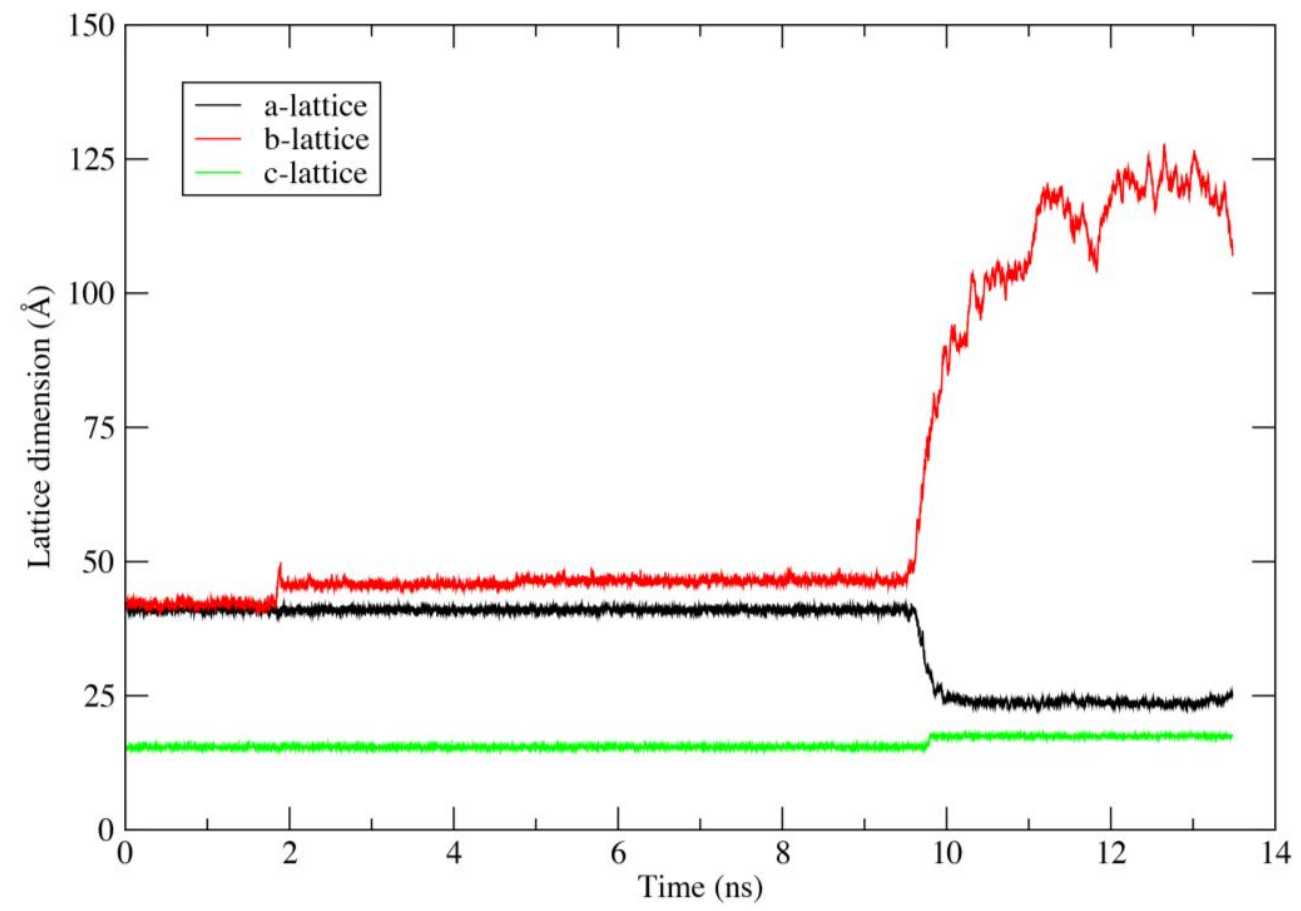

Figure 4. Time dependence of the $a, b$, and $c$ lattice dimensions of the NPT MD simulation of crystalline PCHD at $0 \mathrm{GPa}$ and $590 \mathrm{~K}$.

The aforementioned $\mathrm{T}_{\mathrm{g}}$ values for PCHD with 95\% 1,4-units and 5\% 1,2-units were plotted (Figure S5) as a function of number-average $\left(\mathrm{M}_{\mathrm{n}}\right)$ molecular weight. A linear regression analysis suggests that a molecular weight for 100\% 1,4-units would be around $6700 \mathrm{~g} / \mathrm{mol}$ (i.e., 84 -mers). Though the experimental polymers MW may be greater and more entangled in the amorphous regions than the computed structures, it is expected that $T_{\mathrm{g}}$ and $\mathrm{T}_{\mathrm{m}}$ would not vary by more than a few degrees $( \pm 10 \mathrm{~K})$ between perfectly crystalline and semi-crystalline samples if the structures are larger than the entanglement molecular weight (as observed with UHMW-PE ${ }^{47,57}$ ). 


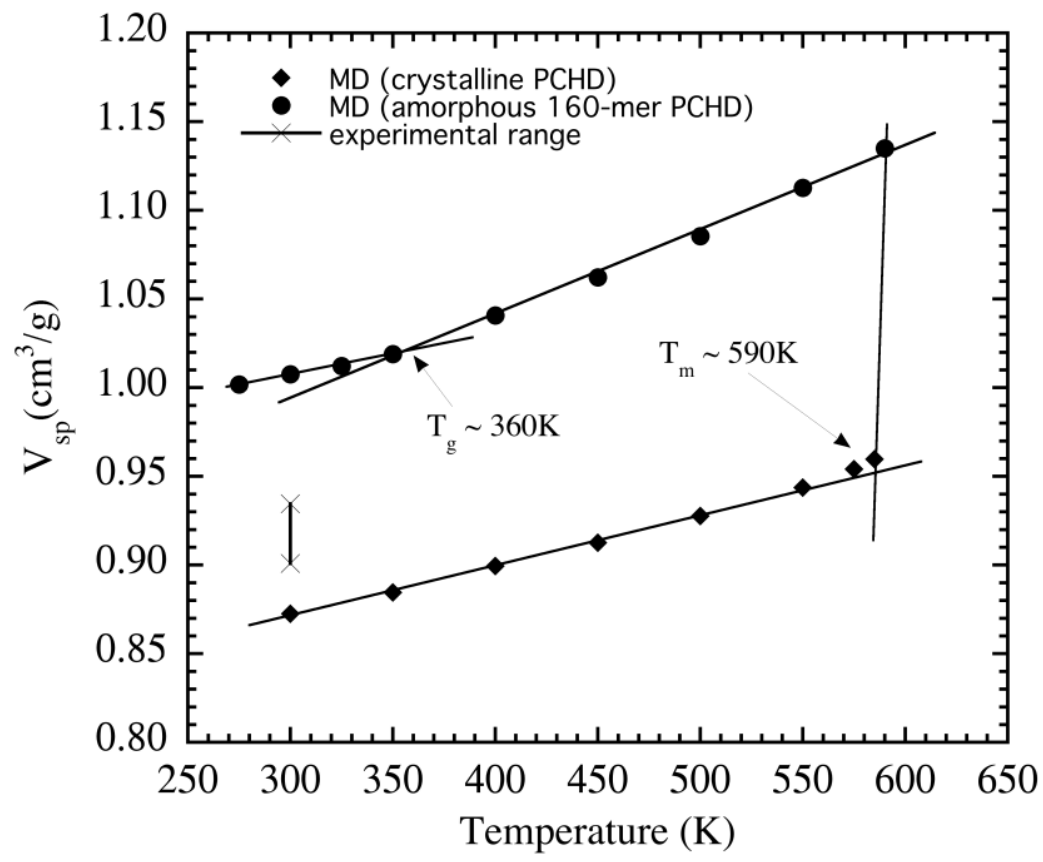

Figure 5. Specific volume as a function of temperature for crystalline (solid diamonds) and 160-mer amorphous (solid circles) PCHD at $0 \mathrm{~Pa}$ as determined from NPT dynamics. Solid lines are linear fits to the data; $\mathrm{T}_{\mathrm{g}}$ and $\mathrm{T}_{\mathrm{m}}$ are labeled explicitly. The range of experimental values is also shown (X symbols; experimental details may be found in the supplementary information (Error! Reference source not found.)).

\section{Conclusion}

Density functional theory (DFT) and molecular dynamics (MD) were used in concert with $\mathrm{x}$-ray diffraction (XRD) and differential scanning calorimetry (DSC) to explore the structural confirmations and transition temperatures of PCHD. DFT geometry minimizations identified the lowest energy conformer; revealing that alternating R,R and S,S chiral bonds between monomer units afford the lowest energy structure. Constructing crystalline PCHD from the minimum energy conformer effectively mimicked the lamellae intermolecular interactions of PCHD as demonstrated through the correlation of DSC data with the temperature dependence of the specific volume derived from MD simulations. The glass/vitrification $\left(\mathrm{T}_{\mathrm{g}}\right)$, crossover/melt-to-crystal $(\mathrm{Tc})$, and melting $\left(\mathrm{T}_{\mathrm{m}}\right)$ transition temperatures of PCHD were identified. The correlation of the calculated transition temperatures with the DSC data reinforces the viability of the calculated monoclinic unit cell consisting of four 4-mer PCHD chains with lattice parameters of $a=9.9$, $b=18.0, c=15.9 \AA$ and $\alpha=\gamma=90^{\circ}, \beta \approx 139^{\circ}$.

\section{Acknowledgements}


This work was performed under the auspices of the U.S. Department of Energy by Lawrence Livermore National Laboratory under Contract DE-AC52-07NA27344. B.S. would like to thank the Eberly Science Foundation for their support of this work. RTM thanks the United Soybean Board for financial support. 


\section{References}

(1) Erdemir, D.; Lee, A. Y.; Myerson, A. S. Acc. Chem. Res. 2009, 42, 621.

(2) Rupp, B. Biomolecular crystallography : principles, practice, and application to structural biology; Garland Science: New York, 2010.

(3) Polymer crystallization : observations, concepts, and illustrations; Sommer, J.-U.; Reiter, G., Eds.; Springer-Verlag: Berlin, 2003.

(4) Tung, H.-H. Crystallization of organic compounds : an industrial perspective; Wiley: Hoboken, N.J., 2009.

(5) Handbook of Transition Metal Polymerization Catalysts; Hoff, R.; Mathers, R. T., Eds.; Wiley: New York, 2010.

(6) Handbook of industrial crystallization; Myerson, A. S., Ed.; Butterworth-Heinemann: Boston, 2002.

(7) De Rosa, C.; Circelli, T.; Auriemma, F.; Mathers, R. T.; Coates, G. W. Macromolecules 2004, 37, 9034.

(8) Schatschneider, B.; Chronister, E. L. J. Phys. Chem. B 2011, 115, 407.

(9) Shi, H.; Zhao, Y.; Jiang, S.; Rottstegge, J.; Xin, J. H.; Wang, D.; Xu, D. Macromolecules 2007, 40, 3198.

(10) Cheng, S. Z. D.; Wu, S. S.; Chen, J.; Zhuo, Q.; Quirk, R. P.; von Meerwall, E. D.; Hsiao, B. S.; Habenschuss, A.; Zschack, P. R. Macromolecules 1993, 26, 5105.

(11) Salim, N. V.; Hanley, T.; Guo, Q. Macromolecules 2010, 43, 7695.

(12) Schultz, J. M. Polymer crystallization; Oxford University Press: New York, 2001.

(13) Fujita, M.; Coates, G. W. Macromolecules 2002, 35, 9640.

(14) Yoon, J.; Mathers, R. T.; Coates, G. W.; Thomas, E. L. Macromolecules 2006, 39, 1913.

(15) Heiser, D. E.; Okuda, J.; Gambarotta, S.; Mülhaupt, R. Macromol. Chem. Phys. 2005, 206, 195.

(16) Natori, I.; Natori, S. Macromol. Chem. Phys. 2006, 207, 1387.

(17) Huang, T. Z.; Wang, X. J.; Malmgren, T.; Hong, K. L.; Mays, J. W. Macromol. Chem. Phys. 2012, $213,49$.

(18) Yang, J. C.; Mays, J. W. Macromolecules 2003, 44, 657.

(19) Huang, T.; Zhou, H.; Hong, K.; Simonson, J. M.; Mays, J. W. Macromol. Chem. Phys. 2008, 209, 308.

(20) Williamson, D. T.; Mather, B. D.; Long, T. E. J. Polym. Sci., Part A: Polym. Chem. 2003, $41,84$.

(21) Wang, Q.; Keffer, D. J.; Deng, S.; Mays, J. Polymer 2012, 53, 1517.

(22) Chen, J.; Alonzo, J.; Yu, X.; Hong, K.; Messman, J. M.; Ivanov, I.; Lavrik, N. V.; Banerjee, M.; Rathore, R.; Sun, Z.; Li, D.; Mays, J. W.; Sumpter, B. G.; Kilbey II, S. M. J. Mat. Chem. A 2013, 1, 13426.

(23) Lee, Y.-H.; Chang, C.-J.; Kao, C.-J.; Dai, C.-A. Langmuir 2010, 26, 4196.

(24) Mathers, R. T.; Shreve, M. J.; Meyler, E.; Damodaran, K.; Iwig, D. F.; Kelley, D. J. Macromol. Rapid Commun. 2011, 32, 1338.

(25) Mathers, R. T. J. Polym. Sci., Part A: Polym. Chem. 2012, 50, 1.

(26) Mao, J. X.; Mathers, R. T.; Damodaran, K. J. Organomet. Chem. 2013, 741-742, 15.

(27) Dakshinamoorthy, D.; Lewis, S. P.; Cavazza, M. P.; Hoover, A. M.; Iwig, D. F.; Damodaran, K.; Mathers, R. T. Green Chem. 2014, 16, 1774

(28) Schroder, K.; Matyjaszewski, K.; Noonan, K. J. T.; Mathers, R. T. Green Chem. 2014, 161673

(29) Natori, I.; Imaizumi, K.; Yamagishi, H.; Kazunori, M. J. Polym. Sci., Part B: Polym. Phys. 1998, $36,1657$.

(30) Longo, P.; Freda, C.; Ruiz de Ballesteros, O.; Grisi, F. Macromol. Chem. Phys. 2001, 202, 409.

(31) Po, R.; Santi, R.; Cardaci, M. A. J. Polym. Sci., Part A: Polym. Chem. 2000, 38, 3004.

(32) Nakano, M.; Yao, Q. Y.; Usuki, A.; Tanimura, S.; Matsuoka, T. Chem. Commun. 2000, 2207.

(33) Quirk, R. P.; You, F.; Zhu, L.; Cheng, S. Z. D. Macromol. Chem. Phys. 2003, 204, 755.

(34) Endo, K.; Uchida, Y.; Matsuda, Y. Macromol. Chem. Phys. 1996, 197, 3515. 
(35) After polymerization of 1,3-CHD with $\mathrm{Ni}(\mathrm{acac})_{2} / \mathrm{MAO}$, attempts to characterize the PCHD with high temperature GPC (in trichlorobenzene) were unsuccessful.

(36) Wilson, E. B.; Decius, J. C.; Cross, P. C. Molecular Vibrations; Dover: New York, 1980.

(37) LAMMPS http://lammps.sandia.gov/.

(38) Plimpton, S. J. Comput. Phys. 1995, 117, 1.

(39) Sun, H.; Mumby, S. J.; Maple, J. R.; Hagler, A. T. J. Am. Chem. Soc. 1994, 116, 2978.

(40) LAMMPS1.

(41) Allen, M. P.; Tildesley, D. J. Computer Simulation of Liquids; Oxford University Press: Oxford, 1989.

(42) Hockney, R. W.; Eastwood, J. W. Computer Simulation using Particles; McGraw-Hill: New York, 1981.

(43) David, W. I. F.; Shankland, K.; Shankland, N. Chem. Comm. 1998, 931.

(44) Engel, G. E.; Wilke, S.; Konig, O.; Harris, K. D. M.; Leusen, F. J. J. J. Appl. Cryst. 1999, 32, 1169.

(45) Gee, R. H.; Fried, L. E. J. Chem. Phys. 2003, 118, 3827.

(46) Gee, R. H.; Lacevic, N.; Fried, L. E. Nature Mat. 2006, 5, 39.

(47) Rastogi, S.; Lippits, D. R.; Peters, G. W. M.; Graf, R.; Yao, Y.; Spiess, H. W. Nature Mat. 2005, 4, 635.

(48) Hong, K.; Huang, T.; Britt, P. F.; Pyda, M.; Mays, J. W.; Polymer Preprints (American Chemical Society, Division of Polymer Chemistry) 2005; Vol. 46, p 843.

(49) Tsige, M.; Taylor, P. L. Phys. Rev. E 2002, 65, 021805.

(50) Roe, R.-J. J. Chem. Phys. 1994, 100, 1610.

(51) Gee, R. H.; Fried, L. E.; Cook, R. C. Macromolecules 2001, 34, 3050.

(52) Bulacu, M.; van der Giessen, E. Phys. Rev. E 2007, 76, 011807.

(53) Han, J.; Gee, R. H.; Boyd, R. H. Macromolecules 1994, 27, 7781.

(54) Gee, R. H.; Boyd, R. H. J. Chem. Phys. 1994, 101, 8028.

(55) Boyd, R. H.; Gee, R. H.; Han, J.; Jin, Y. J. Chem. Phys. 1994, 101, 788.

(56) Gee, R. H.; Boyd, R. H. Comput. Theor. Polym. Sci. 1998, 8, 93.

(57) Lippits, D. R.; Rastogi, S.; Höhne, G. W. H.; Mezari, B.; Magusin, P. C. M. M. Macromolecules 2007, 40, 1004. 


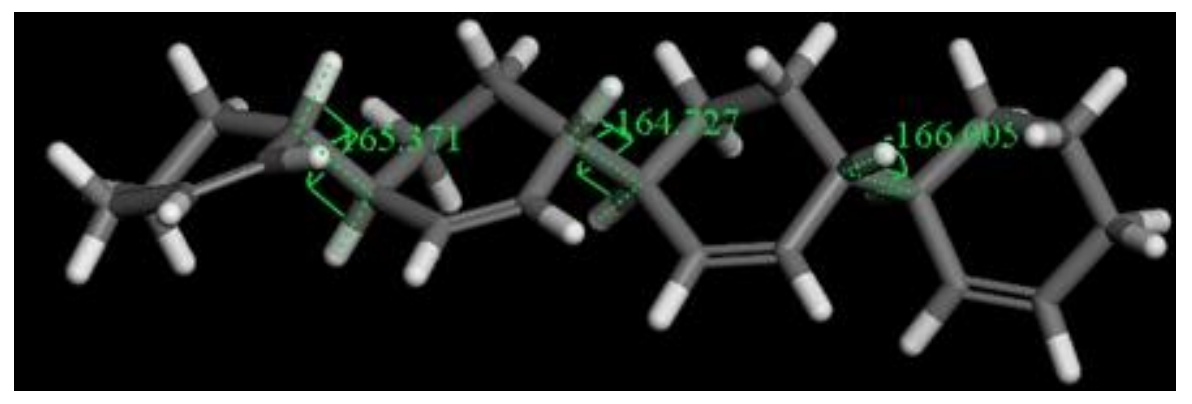

